\title{
LETTERS
}

Send your letters to the editor, British Dental Journal, 64 Wimpole Street, London W1G 8YS or by email to bdj@bda.org

Priority will be given to letters less than 500 words long. Letters should be typed. Authors must sign the letter, which may be edited for reasons of space

\section{Changing names}

Sir, I read, with dismay, in the recent newsletter from the President of the British Association of Oral and Maxillofacial Surgeons, that the British Association of Surgical Dentistry has changed its name, registering it with Company House, to the British Association of Oral Surgeons.

BAOMS evolved out of the original BAOS and is, above all, an inclusive association. Those responsible for this schism, in my view, are merely hindering the advancement of the specialty.

What has occurred, I feel, is a slap in the face to the founding fathers of BAOS, Sir Terence Ward, George Hankey, Norman Rowe, Alan Moule, Fred Monks and Ben Fickling to name but a few.

I have no objection whatsoever to the original name of the 'new' BAOS if some feel strongly the need for a separate body. I am only saddened that this regrettable situation has occurred but this new association should not masquerade under an old name.

\section{J. C Bradley}

Lancashire

doi: $10.1038 / s j . b d j .4811250$

\section{Capitation plans}

Sir, The comments in the letter from $\mathrm{J}$ Hardie (BDJ 2004, 196:187) may be true of his experience of capitation plans in North America, however the position in the UK is rather different.

Denplan Ltd, a provider of such plans in this country, has always held that the fees should be set by the dentist and not by a third party. This avoids the potential for a third party to erode fees over time or to indulge in 'cost-containment' to the disadvantage of both dentist and patient.

Additionally, by encouraging the dentist to carry out an initial assessment, patients can be allocated to one of five 'bands' according to the risk factors they present.

This minimises the risks Dr Hardie describes, where a 'catch-all' fee level is applied to all patients. Whilst dental insurance plans are indeed a solution for some patients, the advantages of capitation are that neither the patient nor the dentist has the added paperwork and delays associated with individual claims, and that for both there is predictability of cost or income.

At this time, many dentists will want to consider the benefits of having alternative sources of funding for their practices, something which the BDA has indeed supported with its current 'Choices'

Seminars.

\section{R. Matthews}

Winchester

doi: 10.1038/sj.bdj.4811251

\section{Fees for the retired}

Sir, I will re-enter the debate on GDC fees for the retired. Increasing the fee for those already fully retired, retrospectively, from $£ 40$ to $£ 388$ at a stroke is nothing but the manipulation of a thousand or so registrants from the register.

Those council members who voted for this should be ashamed. This unconstitutional, retrospective, un-British action against those of us who would eventually depart, yet never be replaced by the fallacy of coupling 'lifelong' learning with the necessary image improving CPD.

To make a point; if a Chancellor of the Exchequer was stupid enough to reduce the state pension by nearly $900 \%$ Parliament would throw it out. Also I question the President's letter to us that we are subsidised by all other registrants.

The Council's own 'pie' diagram in their winter gazette shows only $20 \%$ of the expenditure is down to 'registration' and at $18 \%$ an 'education' expenditure.

The same 'pie' diagram reveals that 55\% is partially dealing with fraud by a few. I cannot see how CPD will affect this substantially. The increasing compensation culture may even put it up. I wonder if the GDC consulted a professional actuary? I know, at the age of 79, what my expectancy is. How long will it be before the ARF is doubled?

I do not need assurance, but I would have liked some common sense from the GDC. It might have been easier, if the pejorative 'lifelong' had never been used.

\section{T. S. Longworth}

Dartmoor

doi: 10.1038/sj.bdj.4811252

Sir, I have read the correspondence you have published about the late notice the General Dental Council gave about the renewal of registration fees and the swinging increase that affected some members of the profession, myself included.

It was the 12th of December when I received the notice concerning the payment of my annual retention fee from the General Dental Council.

I had, indeed, telephoned the GDC only the day before to enquire and was told it was in the post. To find that my registration fee had risen from $€ 40$ to £388 was a shock.

I am no chicken and though retired for three years my former practice occasionally asked me to see a TMJD case. At the time I had two patients under treatment who were having badly worn appliances replaced.

Both had appointments in the new year in order to fit them. I was not prepared to pay £388 to stay on the register and so called the GDC seeking advice over the continuing care of these patients citing the lack of notice of the fee increase.

I could get no further than 'the front office'. The lady was pleasant but unable to pass me on to anyone in authority (out of the office or in a meeting!).

After some cajolery she did seek advice and came back with the re-assurance that as the final deadline for renewing my retention fee was the 9th February she could see no reason why I should not continue their dental care so long as it was completed by that date. I requested confirmation in writing.

They assented but I am still waiting! I know that the GDC were never my employers and functioned as a regulatory body but I was being pushed out of a profession, to which I had contributed 45 years of my life, with utter disregard. I felt I was no longer a dentist but simply a cash cow or a nuisance to be culled. 
We all know this is a new look General Dental Council geared to cope with an ever increasing workload that costs more money and I can appreciate their need for increased funding. Even so I would have thought that to raise the fees so punitively, (in my case from $£ 40$ to $£ 388$ ), needed some months of notice to the profession and much better public relations. To act as they did displayed much ignorance and was both arrogant and insensitive.

I only received their renewal letter with eight working days until the end of the year and was in no position to finish treatment in that time and nobody at the GDC was available to advise me.

I am appaled that any body charged with regulating and maintaining the highest standards of behaviour and professionalism in dentistry could behave in such a way to its own members. I believe an apology would not come amiss. D. Cheetham by email doi: 10.1038/sj.bdj.4811253

\section{Glass ionomer cements}

Sir, The paper by Locker and Jokovic, (BDJ 2003, 195:375) concluded that retention rates for glass ionomer cements used as fissure sealants are substantially lower than that for resin based sealants and their use is not recommended. In view of the fact that this was listed as a verifiable CPD paper it deserves our attention.

The blanket statement that the use of glass ionomer cements is not recommended would appear to ignore the valuable properties of these cements particularly with regard to their adhesion and fluoride release.

The use of GIC has particular value in developing countries where resin bonding requires much more elaborate equipment including curing lights. The hydrophilic nature of these cements also makes application in the field much easier where moisture control can be a major problem.

Locker and Jokovic draw attention to the importance of tooth morphology

\section{Contractual arrangement}

Sir, As 2005 approaches it seems that the government wishes to keep us in the dark about the detail of the new contractual arrangements.

I fear that this is because the contract will contain words of mass defection (WMD's). I would presume that these WMD's are the ones which are to be unleashed on a defenceless and unprepared public and profession with only a 45 minute warning of its contents relating to pits and fissures, which has a significant influence on the risk of caries. Teeth with deep pits and fissures that catch an explorer are the best candidates for sealants while teeth with wide and easily cleaned grooves do not require sealing.

During the development of the glass ionomer cements at The Laboratory of the Government Chemist we addressed the significance of tooth morphology in a paper published on fissure sealing and filling with an adhesive glass ionomer cement (BDJ 1974, 136:269)

We recommended that glass ionomer cements are only suitable as fissure sealants where the pit or fissure orifice exceeds $100 \mathrm{pm}$.

This size of fissure should allow a sharp probe to enter the crevice and is thus clinically detectable. In our clinical study we used a low viscosity cement applied to the fissure with a probe and then pressed a higher viscosity mix over the fissure to force the cement into the crevice.

At that time we used a $50 \%$ solution of citric acid to clean the tooth but later changed to weaker solutions of polyacrylic acid. It should be made clear that in our study fissures were chosen for success and not at random.

A high success rate was recorded for fissure sealants combined with a general maintenance of anatomical form and marginal adaptation: $84 \%$ remained completely intact and caries free after one year and $78 \%$ after 2 years.

We believe that the above recommendations are still valid today. With the introduction of resin modified glass ionomers and faster setting regular GIC's the potential for these cements has improved in relation to our original ASPA cement at LGC.

Whilst agreeing with Locker and Jokovic that resin bonded sealants have proved highly successful and are the materials of choice their dismissal of glass ionomers would appear to neglect the value of their anticariogenic and hydrophilic properties that are not

that the government has been worried about. Perhaps an increase in appropriate intelligence would help the situation.

However, there is light at the end of the tunnel. A colleague informed me that Lord Hutton, following his recent success will be continuing in his role in charge of the government's bleaching policy study group.

\section{Harbour}

Cheshire

doi: $10.1038 /$ sj.bdj.4811255 


\section{Admission statistics}

Sir, I read with interest in a recent edition of the $B D J$ that the admission statistics for a London dental school revealed that as an applicant category, white males were the least likely of all applicant groups to obtain admission as a percentage of applicants.

Interestingly, Trevor Philips, chairman of the Commission for Racial Equality was recently quoted in the Guardian newspaper (March 17th, 2004 )as saying that he wanted more white male students at London Universities where the student population can be as much as $60 \%$ ethnic minority.

Having trained at a London dental school I would put the ethnic population at London dental schools to be far in excess of this figure. I myself am a product of a white single parent family, brought up in council accommodation and for several years homeless, of irish immigrant parents. I am lucky to have obtained degrees in science,dentistry and medicine because of the encouragement

possessed by resin bonded sealants.

Moreover one should remember that the glass ionomer is to be regarded as a longlasting fluoride releasing gel as well as a sealant.

Thus, its protective effect is retained even when the sealant is displaced. This was first noticed by Williams and Winter some decades ago (BDJ 1976, 141:15 and $150: 183)$ when they used glass ionomers for fissure sealing.

Since they did not adhere to the procedures laid down by Wilson and McLean but used those for resin sealants (including acid-etching which is contraindicated), retention over a two-year period of study was poor. However, it is highly significant that they found the incidence of caries was the same as that for a conventional resin sealant.

These results are only to be explained in terms of the protection conferred by longterm fluoride release. Thus retention is not a true measure of the effectiveness of glass ionomer sealants.

\section{J.W. McLean}

\section{A. D. Wilson}

doi: $10.1038 /$ sj.bdj.4811254

\section{Questionnaire research}

Sir, I was most interested to read the editorial on questionnaire research (BDJ 2003, 195:359), particularly since I have recently sent a questionnaire to all 277 individuals whose names currently appear on the General Dental Council's Specialist of good teachers despite difficult circumstances.

There were many of my contemporaries at the time who would have made excellent dental surgeons, who would have jumped at similar opportunities but were not encouraged. Sadly, no concern was, or is shown to this day for this segment of the population who are the forgotten majority.

I am of the opinion that UK dental and medical schools, but especially London dental schools, have failed miserably. Taxpayers have been duped by the universities in the belief of equal access. White working class children deserve places too.

The administrative bodies have made no attempts to include them. Dental school admission officers should take note of Mr Philips comments and bow their heads in shame before being asked to resign.

\section{J. McHugh}

Australia

doi: $10.1038 /$ sj.bdj.4811257

list in restorative dentistry. The purpose of my questionnaire was to attempt to discover information relating to the current practice of restorative specialists in relation to written consent.

It was prompted by a current move by the NHS Trust in which I work towards development of lists of procedures for which consent must be obtained.

Following discussion at our departmental audit and clinical governance group, it was decided that it would be helpful to assess the current practice of our peers, since this may well be helpful as a starting point.

No assistance was directly available from the Trust audit department for my questionnaire, save the provision of 277 reply paid envelopes, since the available funding for audit and research is severely limited.

The questionnaire replies are anonymous, so it is not possible to know who has responded and who has not. In any case, no resources have been made available for a follow-up 'reminder' to any non-responders.

I was initially very pleased to obtain a $65 \%$ response rate from the postal questionnaire, with some respondents replying from as far away as Australia and New Zealand, as judged by the return envelope post mark. However I was dismayed on reading the editorial, and the previous ‘Guidelines for acceptable response rates in epidemiological surveys' (BDJ 1997, 182:68) to find that this response rate would be classified as 'suspect', whilst of course appreciating the arguments in relation to the practice of the unknown non-responders.

Several of my respondents have written comments that they would be interested in the findings of my questionnaire.

I now have a significant amount of information relating to the current practice of restorative specialists in relation to written consent, which I think will make a useful starting point for discussion. It would, however, be extremely helpful if those restorative specialists who have not yet responded could do so now. An improved response rate will assist in verifying the validity of this information which will be of benefit to all.

\section{H. Beckett}

Portsmouth

doi: $10.1038 /$ sj.bdj.4811256

\section{Postoperative antibiotics}

Sir, I am not an academic practitioner and so I relate this tale with no empirical evidence apart from what my nurse and I have noticed in our oral surgery practice.

About 18 months ago I attended a course given by Professor Mike Martin (he of microbiology, GDC and Somerset beer drinking fame) at which he told us firstly that there has never been any real reason why antibiotics should be given for five days after surgery, and secondly, we should use only one $200 \mathrm{mg}$ tablet of metronidazole at the time of surgery instead. Many of us were sceptical but I decided to give it a try and from that day to this, I routinely give just one $200 \mathrm{mg}$ tablet of metronidazole at the time of surgery (some authorities suggest one hour before surgery) when doing any apicectomy or wisdom tooth - however messy or infected they are beforehand.

To date, I have not had one single case of postoperative infection in approximately 70 operations performed, and neither have I changed my technique! Beforehand I would expect at least one case every month or so.

So on the face of it, Professor Martin's suggestion is a good one. I reiterate my observations are not tested empirically but perhaps some enterprising person would like to take it on? In the meantime I urge colleagues to review their own postoperative antibiotic regimes - perhaps this regime will work for them? It would certainly reduce the quantity of antibiotics dispensed and taken by the general public on our instructions.

\section{R. Kitchen}

Bristol

doi: 10.1038/sj.bdj.4811258 


\section{Oral health educators}

Sir, I can understand why Professor Blinkhorn and colleagues express disappointment with the results of their study of oral health educators in general dental practice (BDJ 2003, 195:395) but I wonder if they are correct to be downhearted? In the NHS, every initiative has an opportunity cost, and this study shows that the intervention might not be a cost-effective choice for PCTs making difficult choices about funding for local dental services. This is a worthwhile finding.

The results moreover, (an improvement in parental knowledge, attitudes and skills, but no statistically significant impact on children's disease levels), are by no means surprising. Kay and Locker's systematic review ${ }^{1}$ concluded that oral health promotion was effective for increasing knowledge levels, but there was no evidence that changes in knowledge were causally related to changes in behaviour.

The way forward may therefore be to move 'upstream' as recommended recently by Sheiham and Watt ${ }^{2}$, by tackling the determinants of poor health, and taking community-wide measures to make it easier for parents to make healthy choices on behalf of their children ${ }^{2}$. Nor should dental health education in the surgery setting necessarily be abandoned completely, as a result of the findings of Blinkhorn et al's study.

The dedicated dental health educators employed in the trial to provide intensive counselling seem not to have been costeffective. However, the provision of inhouse surgery-based, simple, scientifically sound, preventive advice to parents of children at high risk of, or already suffering from, caries must still be an ethically correct component of a much broader health promotion approach. As the authors note that there are significant barriers to dentists providing this service at present, perhaps other less costly models could be tested to try to overcome them.

\section{Stillman-Lowe}

\section{Twyford Reading}

doi: 10.1038/sj.bdj.4811259

1. Kay E J, Locker D. Effectiveness of oral health promotion: a review. London: Health Education Authority, (1997).

2. Sheiham A, Watt R. Oral health promotion and policy. Murray J J, Nunn J H, Steele J G (eds). The Prevention of Oral Disease. 4th ed, pp 241-257. Oxford: Oxford Medical Publications, 2003.

\section{Hygienist training}

Sir, I am currently undertaking postgraduate research into the attitudes towards the use of dental auxiliaries
(PCDs) across the world, particularly in the EU.

My research will show that the data for Greece and Portugal are different than quoted by Dr Antonarakis in his letter (BDJ 2004, 196:127) and the different views about the use of PCDs are very complex. Until all the factors are understood there is no chance of any consensus on the training and duties of dental hygienists.

The EU Manual of Dental Practice $2004^{1}$, to be published in May 2004, will show the population to active dentist ratios of Greece and Portugal are 1,246 (2002) and 2,240 (2001) respectively. There are no hygienists in Greece and there were 150 hygienists in Portugal (about one for every 30 dentists). The respective DMFTs at 12 years were 1.80 and $1.50^{2}$.

The (current) EU/EEA country with the highest population to active dentist ratio is Spain, at 2,672. There are 9,000 practising hygienists in Spain, (about one for every two dentists) - yet the DMFT in 2002 was $2.30^{2}$.

The six countries with similar low population to active dentist ratios as Greece were the Nordic countries (Denmark, Finland, Iceland, Norway and Sweden) together with Italy - all of which also have high numbers of practising hygienists.

Whilst four of these countries have low DMFTs (around 1.0 at 12 years), perversely Iceland and Italy have high DMFTs (2.7 and 2.12 respectively) ${ }^{2}$. I have not yet been able to ascertain any obvious connection between the various methods of service delivery and DMFT, to form any conclusions.

\section{A. S. Kravitz}

\section{Manchester}

\section{doi: 10.1038/sj.bdj.4811260}

1. EU Manual of Dental Practice 2004, Kravitz A, Treasure E. To be published by the EU Dental Liaison Committee, May 2004

2. The Council of European Chief Dental Officers, http://www.cecdo.org and the World Health Organisation, www.whocollab.od.mah.se/euro/eu/eurofr.html

\section{Appropriate insurance}

Sir, I write regarding S. Mynard's letter in $B D J$ 2004, 196:248. In respect of the 'legal loophole', there is unfortunately nothing new in this complaint.

Some three years ago, I wrote to Professor Nairn Wilson asking why the General Dental Council did not make it a compulsory requirement for proof of appropriate insurance to be provided before registration on the General Dental Council list. I was informed at that time that they shared my concerns, but there were difficulties as far as administration was concerned.

Some three years later, this still seems to be the position, and I would agree with the letter writer that this is quite unsatisfactory.

In the matter of whether or not the insurance taken out should be discretionary or indemnity, this is not a simple matter.

If there has been evidence of fraud etc, insurance companies may well void policies. There has been considerable complaint that discretionary bodies do make their own judgements in whether or not cases should be taken forward, but my experience of insurance has unfortunately led me to the conclusion that unless all conditions of the policy are adhered to, indemnity insurers can also use exclusion clauses not to pay out to their policy holders.

However, these difficulties are not a reason for patients to be refused compensation because of failure either on the part of the dentist or insurers, and this matter does need urgent addressing if the public is to have confidence in us as a professional body.

\section{A. R. Halperin}

by email

doi: 10.1038/sj.bdj.4811261

\section{Slimy problem}

Sir, I read Dr P D Copson's letter (BDJ 2004, 196:248) describing the use of a rubber swimming hat to prevent the transmission of head lice from patient to operator, with great interest. He does not, however, specify as to whether the hat should be worn by the patient or the operator.

As an orthodontist, my 'hairy' problem is that of excessive hair gel applied by my adolescent male patients. They enter the surgery with gel-assisted spiky hair (looks rather like the meringue on a baked Alaska - a modern trend in these parts), and leave with a flattened style (reminiscent of Frankenstein's Monster).

The result of this? The shirt of the operator covered in the slimy concoction. This is not only uncomfortable, but is likely to create some embarrassment when the next patient walks in.

The obvious remedy to this is to apply a bath cap to the patient's head preoperatively (readily available from most high street chemists and good conference hotels). For repeat offenders the threat of using a pink one seems to be an effective deterrent.

\section{P. M. Noble}

Nottingham

doi: $10.1038 /$ sj.bdj.4811262 